\title{
Patente Canvas: Transformando a Maneira de Criar Patentes Inovadoras*
}

\author{
Patent Canvas: Transforming the Way to Create Innovative Patents
}

Patente Canvas: la Transformación de la Manera de Crear Patentes Inovadoras

Fernando Kobuti Ferreira', Elaine Horibe Song ${ }^{1}$, Elvio Bueno Garcia ${ }^{1}$

Inspirado no conhecido e renomado "canvas" do livro Business ModelCanvas, de Alexander Osterwalder e Yves Pigneur, o Patente Canvas é uma ferramenta para auxiliar no planejamento e criação de patentes inovadoras.

O Patente Canvas aborda os principais pontos que são essenciais para entender e avaliar o potencial de qualquer patente. É um mapa visual pré-formatado que contém onze blocos do modelo de negócios de uma patente inovadora. Ele permite relacionar as informações de forma sistêmica, integrada e rápida. A ferramenta é bastante útil para discutir e integrar percepções sobre a maneira como a patente gera valor.

O Patente Canvas pode ser acessado por meio de um e-book disponível no site: <http://www.patentecanvas.com>.

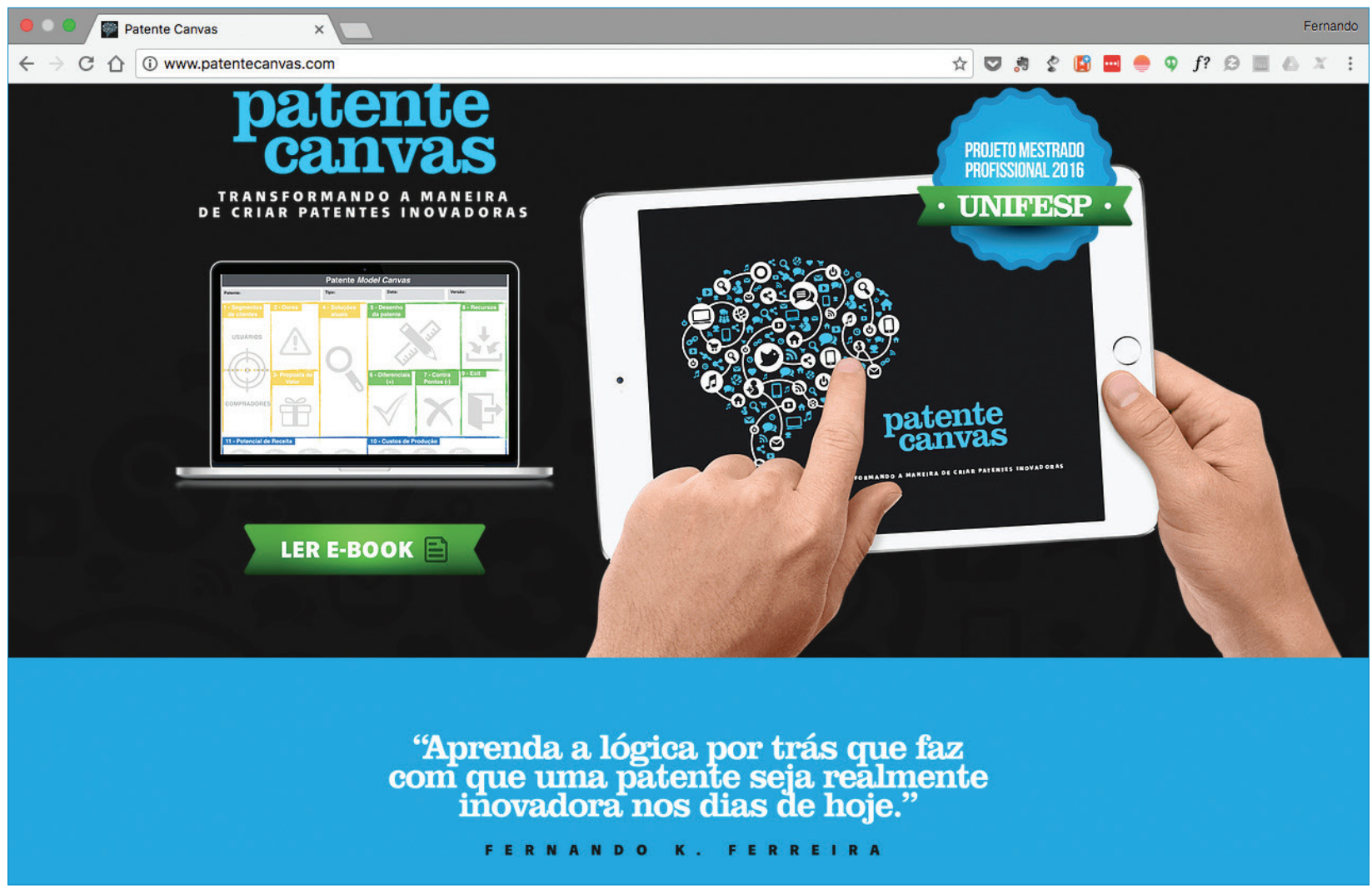

Figura 1. Site: patentecanvas.com.

*Dissertação apresentada ao Curso de Mestrado Profissional em Ciência, Tecnologia e Gestão aplicadas à Regeneração Tecidual da Universidade Federal de São Paulo (UNIFESP), defendida em 20 de maio de 2016.

'Universidade Federal de São Paulo (UNIFESP). Endereço para correspondência: Rua Napoleão de Barros, 715, $4^{\circ}$ andar - Vila Clementino -

CEP: 04024-002 - São Paulo (SP), Brasil - E-mail: fernando.k.ferreira@gmail.com

Artigo recebido em: 05/06/2016 - Aceito para publicação em: 08/07/2016 


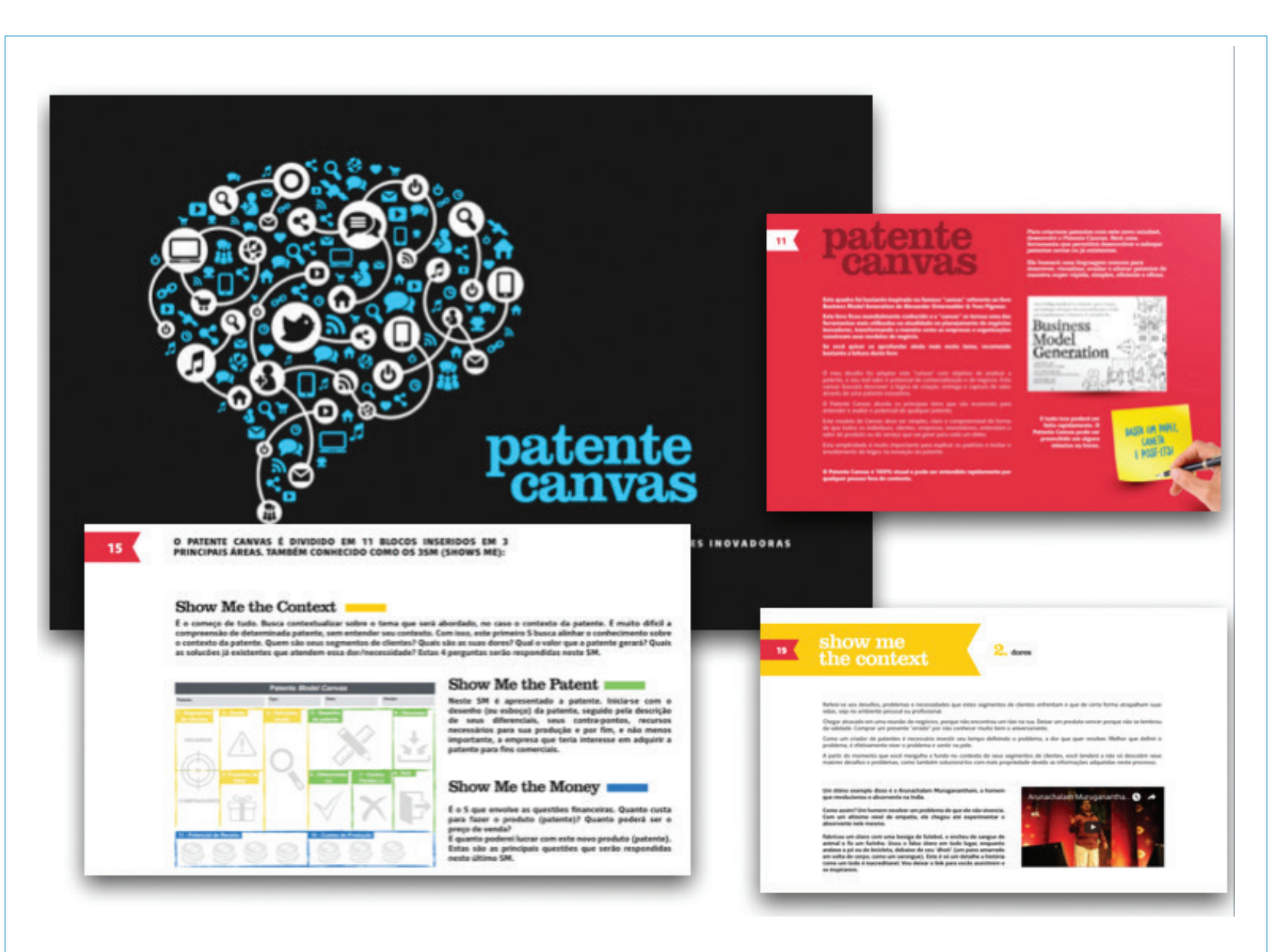

Figura 2. E-book Patente Canvas.

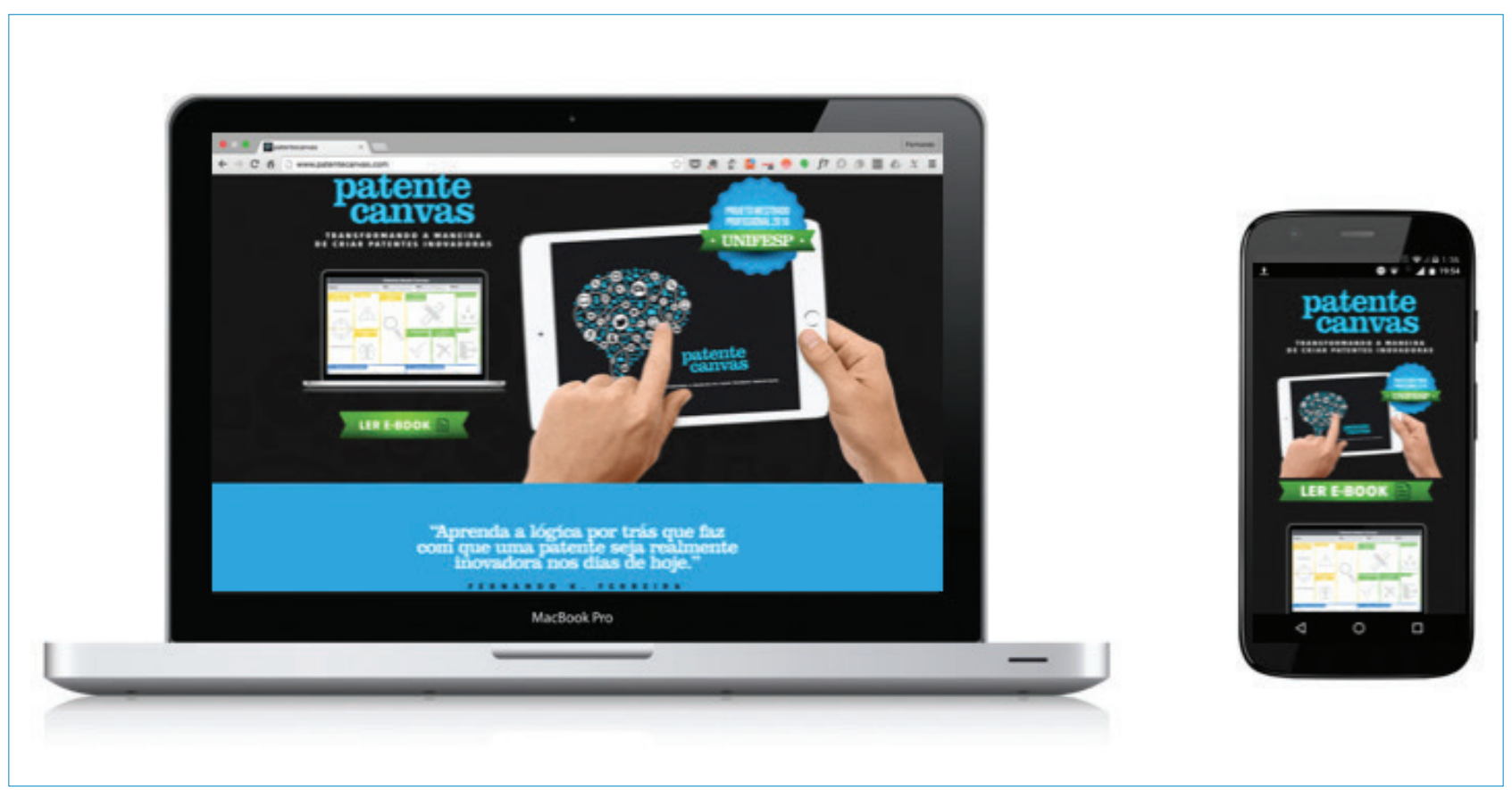

Figura 3. Patente Canvas | Versão PC e Mobile. 




Figura 4. Patente Model Canvas. 